\title{
Hepatitis B surface antigen detection using pooled sera. A cost-benefit analysis
}

\author{
E. Fernández, L. Rodrigo ${ }^{1}$, S. García, S. Riestra ${ }^{1}$ and C. Blanco \\ Service of Biochemistry. Hospital de Cabueñes. Gijón. ' Service of Gastroenterology. Hospital Central de Asturias. \\ Oviedo. Spain
}

\begin{abstract}
Objectives: to examine the feasibility and to perform a cost benefit analysis of a 5-sample pooling strategy using an enzyme immunoassay (EIA) for the screening of hepatitis B surface antigen (HBsAg).

Material and methods: to assess the sensitivity and specificity of the pooling method, each of the 40 positive sera (from weak to intensely HBsAg-positive) and 250 negative sera were tested in a pool with $4 \mathrm{HBsAg-negative} \mathrm{sera.} \mathrm{The} \mathrm{limit} \mathrm{of} \mathrm{detection} \mathrm{for} \mathrm{HB}-$ $\mathrm{sAg} / \mathrm{ad}$ and $\mathrm{HBsAg} / \mathrm{ay}$ was evaluated using sera from a panel of purified subtypes. A study under real conditions was conducted using pools from 340 pregnant women.

Results: the sensitivity and specificity of this technique were $100 \%$. The correlation coefficient among the sample/cutoff ratios of 40 samples studied in single and in pooled conditions was 0.792 ( $p<0.005)$. The pooling method has lower levels of detection for $\mathrm{HBsAg} / \mathrm{ad}$ and $\mathrm{HBsAg} / \mathrm{ay}$ at $0.20 \mathrm{ng} / \mathrm{mL}$ and 0.12 $\mathrm{ng} / \mathrm{mL}$, and the single method at $0.34 \mathrm{ng} / \mathrm{mL}$ and $0.29 \mathrm{ng} / \mathrm{mL}$, respectively. The pooling method loses no sensitivity for values up to $100 \mathrm{IU} / \mathrm{L}$ of anti-HBs in the four sera mixed with a positive serum. The cost-benefit analysis showed that the pooling method could save from $30 \%$ up to $75 \%$ of the cost of HBsAg determination, according to whether seroprevalences were $10 \%$ or $1 \%$, respectively.

Conclusions: the pooled HBsAg EIA yielded no worse than the single EIA test, and was a cost-effective and valid strategy in areas with a high, medium or low prevalence.
\end{abstract}

Key words: Hepatitis B surface antigen. Pooling sera. Cost-benefit analysis.

Rodrigo L, Fernández E, García S, Riestra S, Blanco C. Hepatitis $B$ surface antigen detection using pooled sera. A costbenefit analysis. Rev Esp Enferm Dig 2006; 98: 112-121.

Recibido: 31-05-05.

Aceptado: 13-10-05.

Correspondencia: Luis Rodrigo. Servicio de Aparato Digestivo. Hospital Central de Asturias. C/ Celestino Villamil, s/n. 33006 Oviedo. Fax: 985 273 614. e-mail: lrodrigos@terra.es

\section{INTRODUCTION}

Hepatitis B virus (HBV) infection is a disease affecting millions of people worldwide. Its main reservoir is that of chronic HBV carriers. It is estimated that some 300 million people throughout the world are infected by this virus (1). The medical consequences of HBV infection are both variable and unpredictable, depending on factors such as patient age and immune status. HBV is a well recognized etiologic agent for chronic hepatitis, liver cirrhosis, and hepatocellular carcinoma.

Great differences exist, however, in the prevalence of the infection, and this has led to the establishment of three major areas of high, medium, and low endemicity (2). In most developed countries, the prevalence of chronic HBV carriers is less than $2 \%$, and infection transmission takes place, above all, in adults belonging to certain risk groups (drug users, homosexual men, promiscuous heterosexuals, health workers) (3). In Spain, a 1.2\% prevalence of HBV carriers has been found (4), and the identification of $\mathrm{HBsAg}$ in blood donors, pregnant women and subjects undergoing auto-transfusion programs is mandatory.

The serum pooling technique attempts to reduce costs without losing efficacy, and has been mainly used in developing countries in the search for antibodies against the human immunodeficiency virus (HIV) (5-14), and hepatitis C virus (HCV) (15-19). The results obtained with this method have proved highly promising, as they have significantly decreased the cost of laboratory tests without significantly decreasing their sensitivity.

The present study attempts to assess whether the serum pooling technique is applicable in the detection of HBsAg to elucidate the factors that may modify its sensitivity, and to perform a cost-benefit analysis for this diagnostic technique. 


\section{MATERIAL AND METHODS}

\section{HBsAg determination}

The Imx HBsAg assay (Abbott Laboratories, Abbott Park, IL), which is a qualitative third-generation microparticle Enzyme Immunoassay (EIA), was used for HBsAg assessment. The presence or absence of HBsAg is determined by comparing the rate of fluorescent product formation to a cutoff, which is calculated from the negative calibrator $(\mathrm{N})$ rate (human plasma nonreactive for HBsAg). The Imx HBsAg assay calculates a ratio of the sample $(\mathrm{S})$ rate to the negative calibrator rate. The cutoff value $(\mathrm{S} / \mathrm{N})$ was established as 2 for the singleserum EIA.

The pooling technique is carried out by adding $200 \mathrm{mcL}$ to the pool, that is, by obtaining a mixture of $40 \mathrm{mcL}$ of each of the 5 sera making up the pool (dilution 1/5). The cutoff was established as the mean for negative samples plus 3 standard deviations, thus yielding a value of 1 . It is considered, therefore, that a non-reactive sample exists in this group of 5 when the $\mathrm{S} / \mathrm{N}$ coefficient is < cutoff value, while an S/N pool > cutoff may indicate the presence of at least one reactive sample. In this case, it is necessary to retest individual samples in order to identify the reactive sample (s). All tests are performed in duplicate.

In accordance with the above, specificity was evaluated by HBsAg assessment in 50 pools of 250 negative sera. In order to calculate sensitivity, 40 sera with the same concentration distribution as the general population from which they were sampled [ranging from weak to intensely $\mathrm{HBsAg}$ positive $(\mathrm{S} / \mathrm{N}$ single $=2.06-154.9)]$ were tested in a pool with 4 negative sera.

\section{HBsAg subtypes (ad and ay)}

The limit of detection of Imx HBsAg for ad and ay was evaluated using sera from a panel of purified $\mathrm{HBsAg}$ subtypes (hepatitis HBsAg sensitivity panel, Abbott Laboratories). HBsAg/ad and HBsAg/ay concentrations ranged from 0.13 to $2.32 \mathrm{ng} / \mathrm{mL}$ and from 0.21 to 2.24 $\mathrm{ng} / \mathrm{mL}$, respectively. The limit of detection was determined in single and in a pool with $4 \mathrm{HBsAg}$ negative sera.

\section{Influence of anti-HBs level}

In order to ascertain whether the existence of anti-HBs antibodies in the sera studied using the pooled test might neutralize HBsAg and interfere with the technique's sensitivity we applied the method of pooling a serum with a known concentration of $\mathrm{HBsAg} / \mathrm{ad}$ and $\mathrm{HBsAg} / \mathrm{ay}$ with four sera with known titers of anti-HBs.
The quantitative determination of anti-HBs was carried out with a microparticle Enzyme Immunoassay (mEIA) method using an AxSYm autoanalyzer (AxSYm ${ }^{\mathrm{TM}} \mathrm{AUSAB}$, Abbott Laboratories, Abbott Park, IL). Sera with high antiHBs titers were obtained from post-vaccinated HBV controls and patients who have recovered from hepatitis B.

\section{Pool-test in screening of HBsAg}

In order to assess the validity of pool testing, a simulation of field operations was conducted using the above method on 1,525 serum samples obtained from pregnant women in a previous study by us to estimate the prevalence of $\mathrm{HCV}$ infection, and whose samples were stored at $-20{ }^{\circ} \mathrm{C}$ since collection. We randomly selected 300 negative $\mathrm{HBsAg}$ and 14 positive HBsAg samples from these. Determinations were made with no previous knowledge of pool compositions.

\section{Reduction in number of tests}

When a pool results positive, it is necessary to individually retest each component in order to identify the sample or samples that are HBsAg-positive. Thus, the greater the number of positive pools (that is, the prevalence of HBsAg), the smaller the reduction in the number of tests performed.

On this basis, the percentage reduction in the number of tests when pooled sera screening for HBsAg was used, was calculated under the most unfavorable and unlikely conditions (low prevalence), that is, when not more than one positive serum was present in any of the pools. For example, for an HBsAg seroprevalence of 2\%, if 100 sera are analyzed in 20 pools, 2 of these will be positive. So, it is necessary to add 10 determinations (10 sera retested individually) to the 20 initial ones ( 20 pools), this yielding 30 determinations in total. In this example, $70 \%$ of the cost could be saved. In order to carry out a cost-benefit analysis, the price of HBsAg testing was estimated to be 3 US dollars for each sample. This being based on the average actual price of the commercial kit in our hospital.

\section{Statistical analysis}

Data were collected in a database and later analyzed using the statistical package SPSS for Windows, Release 10.0. Spearman's non-parametric linear correlation was employed. Results are expressed as mean $\pm \mathrm{SD}$. A level of $p<0.05$ was considered statistically significant.

\section{RESULTS}

None of the 50 pools of HBsAg-negative sera resulted positive ( $\mathrm{S} / \mathrm{N}$ pool $>1)$, and the following values of $\mathrm{S} / \mathrm{N}$ pool were obtained: $0.767 \pm 0.076$ (range 0.67-0.88). 
With this sample, the specificity of this pooling technique was therefore $100 \%$. On the other hand, all $40 \mathrm{HBsAg}$ positive sera, when determined in pooled form, yielded $\mathrm{S} / \mathrm{N}$ values greater than 1 (with sensitivity also being $100 \%$ ). The correlation coefficient among $\mathrm{S} / \mathrm{N}$ ratios for these 40 samples as studied in single and in pool was $0.792(\mathrm{p}<0.05)$.

Twenty-six point six percent of pools with samples having high HBsAg titers had an $\mathrm{S} / \mathrm{N}$ ratio even greater than the single sample. However, the correlation coefficient of samples with low HBsAg titers ( $\mathrm{S} / \mathrm{N}$ single $<25$, $\mathrm{n}=12$ ) was excellent $(\mathrm{R}=0.9739, \mathrm{p}<0.05)$, as can be seen (Fig. 1).

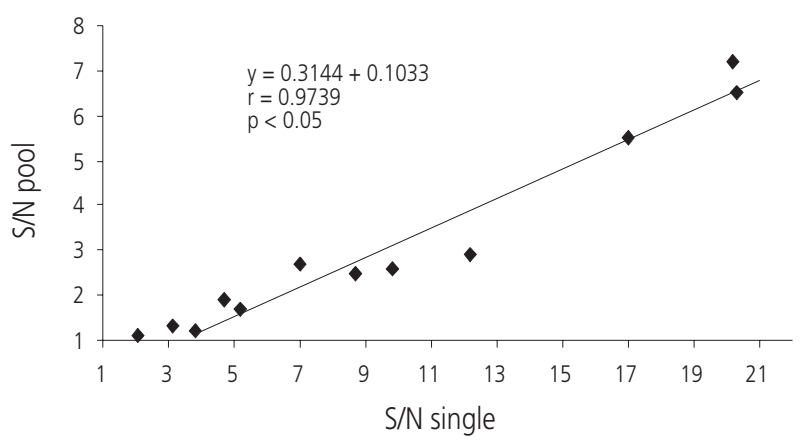

Fig. 1.- Correlation among the $S / N$ ratios of samples with low titres of HBsAg ( $\mathrm{S} / \mathrm{N}$ single $<25)$ when tested single and in pool (S: sample rate; $\mathrm{N}$ : negative calibrator rate).

Correlación entre los cocientes S/N de las muestras con títulos bajos de HBsAg (S/N single < 25) determinados con el método simple y en mezcla ( $S=$ muestra; $N=$ calibrador negativo).

The limit of detection using the single method was $0.34 \mathrm{ng} / \mathrm{mL}$ for the ad subtype and $0.29 \mathrm{ng} / \mathrm{mL}$ for the ay subtype, while for the pooling method lower levels of antigen were detected: $0.20 \mathrm{ng} / \mathrm{mL}$ and $0.12 \mathrm{ng} / \mathrm{mL}$, respectively. The results of applying the single and pooled techniques to sera with different concentrations of HBsAg/ad and HBsAg/ay are shown (Fig. 2).

When the anti-HBs titer in the pool is less than $100 \mathrm{IU} / \mathrm{L}$, the technique does not lose sensitivity; even when anti-HBs titers reach 10,000 IU/L, the technique is still capable of detecting HBsAg concentrations as low as $1.5 \mathrm{ng} / \mathrm{mL}$. The influence of the different concentrations of anti-HBs on the limit of detection for HBsAg subtypes when using the pooling method are presented (mean of 2 determinations) (Fig. 3).

In the investigation carried out under real conditions in the sera of pregnant women, the method of pooling resulted in the correct classification of all samples analyzed. Consequently, sensitivity and specificity were $100 \%$.

There is a decrease in the percentage of reduction in the number of tests achieved with the pooling method as

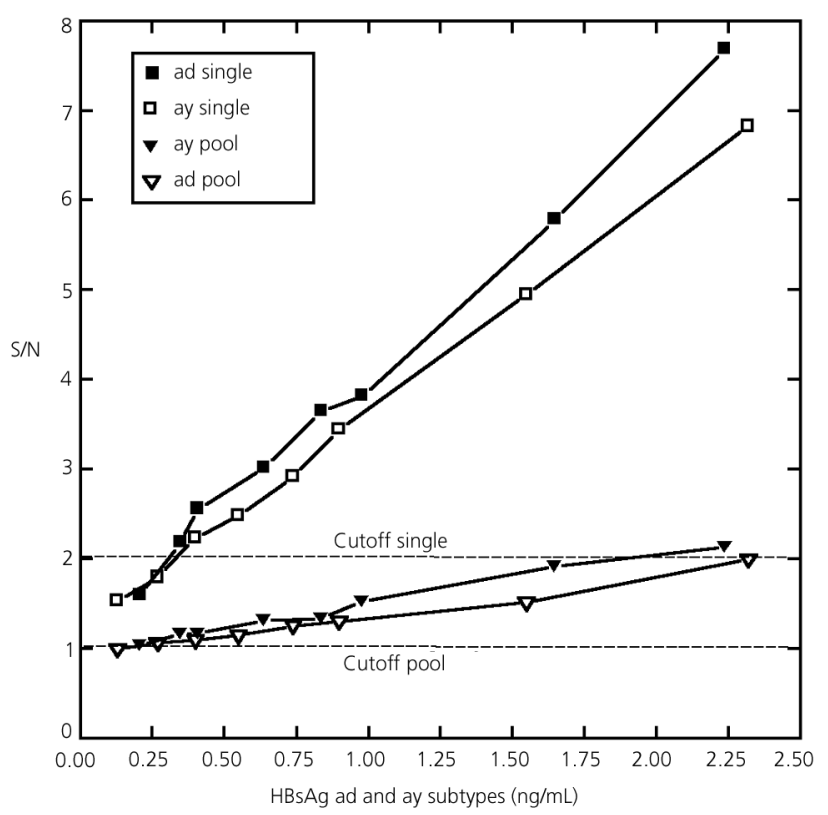

Fig. 2.- Detection limits for HBsAg/ad and HBsAg/ay subtypes using the single sample method $(\square, \boldsymbol{\nabla})$ and the sample pooling method $(\nabla, \boldsymbol{\nabla})$. Lower levels of antigen were detected with the pooled test $(0.20 \mathrm{ng} / \mathrm{mL}$ and $0.12 \mathrm{ng} / \mathrm{mL}$, respectively) when compared to the single test $(0.34$ $\mathrm{ng} / \mathrm{mL}$ and $0.29 \mathrm{ng} / \mathrm{mL}$, respectively) ( $\mathrm{S} / \mathrm{N}=$ sample rate/negative calibrator rate; $\mathrm{S} / \mathrm{N}$ in single $>2.0$ and $\mathrm{S} / \mathrm{N}$ in pool $>1.0$ are interpreted to be reactive).

Límites de detección para los subtipos HBsAglad and HBsAglay mediante el método simple ( $(\square, \mathbf{D})$ y el método de mezcla $(\nabla, \mathbf{\nabla})$. Se detectaron niveles menores con el método de mezcla $(0,20 \mathrm{ng} / \mathrm{mL}$ y 0,12 $\mathrm{ng} / \mathrm{mL}$, respectivamente) que con el método simple $(0,34 \mathrm{ng} / \mathrm{mL}$ y 0,29 $n g / m L$, respectivamente) ( $S / N=$ muestra/calibrator negativo; se consideran positivos valores de $S / N$ en simple $>2,0$ y S/N en mezcla).

the seroprevalence of HBsAg increases. It can be seen that even with HBsAg prevalences as high as $10 \%$ in the sample studied, a minimum saving of at least $30 \%$ is reached (Fig. 4).

The analysis of the economic benefits of the serum pooling strategy shows that the savings achieved depend on both the prevalence of HBsAg and the number of determinations to be made. Thus, for countries with a low prevalence such as ours, the pooling method reduces testing cost for HBsAg. For example, we estimated that in 2,500 determinations performed in a laboratory during one year using the pooling method, savings will be 5,630 US dollars, and in the case of a very busy hospital performing 20,000 determinations annually, savings will reach 45,000 US dollars (Table I).

\section{DISCUSSION}

An approach to the pooling method is to maintain the dilution and final volume of the reaction mixture in each 

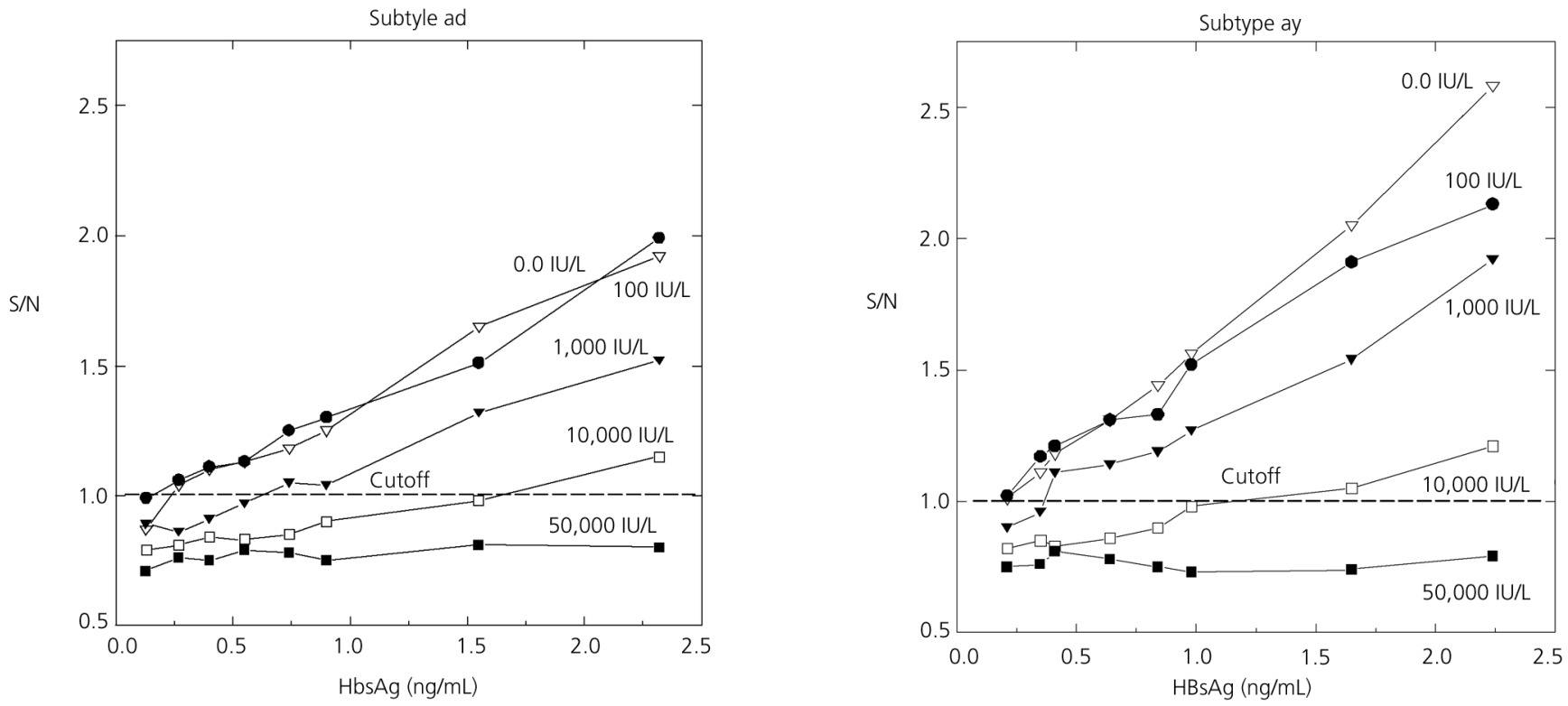

Fig. 3.- Neutralizing effect of anti-HBs at different titers ( $\nabla: 0.0 \mathrm{IU} / \mathrm{L} ; \bullet: 100 \mathrm{IU} / \mathrm{L} ; \mathbf{\nabla}: 1,000 \mathrm{IU} / \mathrm{L} ; \mathrm{\square}: 10,000 \mathrm{IU} / \mathrm{L} ; \mathbf{\square}: 50,000 \mathrm{IU} / \mathrm{L})$ on low concentrations of HBsAg ad and ay subtypes. Values below dotted line (cutoff) were not detected when determined in pooled form ( $\mathrm{S} / \mathrm{N}=\mathrm{sample}$ rate/negative calibrator rate; $\mathrm{S} / \mathrm{N}>1.0$ is interpreted to be reactive).

Efecto de neutralización del anti-HBs a diferentes títulos ( $\nabla$ : 0,0 IU/L; $\bullet: 100 \mathrm{IU} / \mathrm{L} ; \mathbf{\nabla}: 1.000 \mathrm{IU} / \mathrm{L} ; \mathrm{a}: 10.000 \mathrm{IU} / \mathrm{L} ; \mathbf{\square}: 50.000 \mathrm{IU} / \mathrm{L})$ sobre concentraciones bajas de los subtipos HBsAg ad y ay. Los puntos bajo la línea discontinua (punto de corte) no fueron detectados al determinarse en mezcla (se toma como positivo un valor de $S / N>1,0$ ).

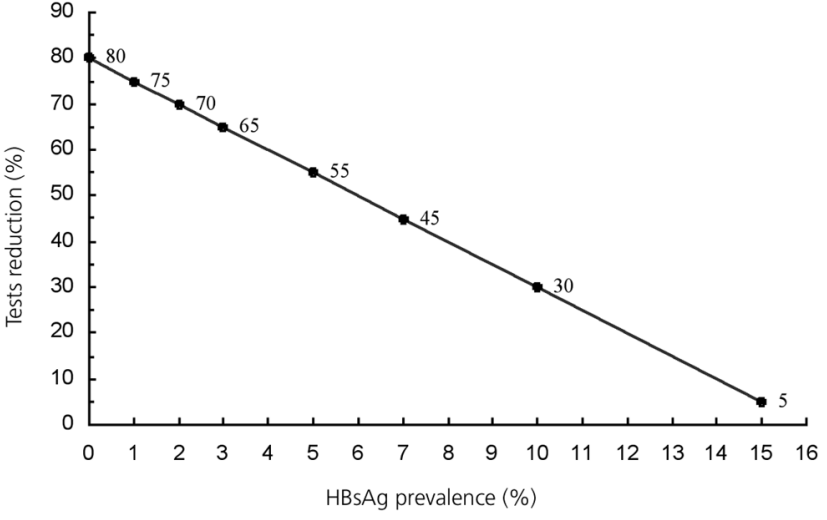

Fig. 4.- Percentage reduction in the number of tests performed when the serum pooling method is used according to HBsAg prevalence. Estimates were made supposing that no more than one positive serum is present in each pool.

Porcentaje de reducción en el número de tests realizados con el método de mezcla sérica de acuerdo a la prevalencia de HBsAg. El cálculo se hizo en el supuesto de que no hay presente más de una muestra positiva en cada mezcla.

pooled test in order not to lose sensitivity, for which the diluent is reduced, and partly replaced by the additional sera. In this way it is not necessary to modify the cutoff value with respect to the standard method in individualized samples. However, the method used in our study was
Table I. Cost savings (thousands of dollars) when the serumpooling strategy is used according to HBsAg seroprevalence and number of samples to be tested

\begin{tabular}{lcccc}
\hline & \multicolumn{4}{c}{ HBsAg seroprevalence } \\
\hline No. samples/year & $1 \%$ & $2 \%$ & $5 \%$ & $10 \%$ \\
\hline 2,500 & 5.63 & 5.25 & 4.12 & 2.25 \\
5,000 & 11.25 & 10.5 & 8.24 & 4.5 \\
10,000 & 22.5 & 21 & 16.5 & 9 \\
20,000 & 45 & 42 & 33 & 18 \\
\hline
\end{tabular}

automated and sample dilution was performed by an autoanalyzer. For this reason, each sample shows a dilution of 1 in 5 on being mixed with the other 4 sera. Therefore, it was necessary in our study to modify the cutoff value and limit the number of sera in the pool in order not to lose sensitivity.

Regarding specificity, it is necessary to remark that the mean value for pools was only just over 3 standard deviations from the cutoff. Thus, a false positive might be expected in about $1 \%$ of occasions. We think that this is acceptable as specificity is nearly $100 \%$ (99.9\%). A study with a greater number of negative samples from a large number of different individuals will be required in order to establish the true specificity of this assay. 
Although the correlation between single and pooled sample testing is good, the regression line intercepts the $\mathrm{X}$ axis at an $\mathrm{S} / \mathrm{N}$ ratio of 3 (the corresponding $\mathrm{Y}$ value is 1 ). This may mean that any sample with an $\mathrm{S} / \mathrm{N}$ ratio between 2 and 3 in the single sample test would have a value below 1 and would therefore not be detected in the pooled test.

For a prevalence of $1 \%$ of $\mathrm{HBsAg}$-positive sera, a mathematical model described by Liu et al. (19) achieved the maximum reduction $(80.5 \%)$ in the number of tests for a pool size of 11 sera. However, in our opinion, a problem might arise with specificity due to the effect of pooling on the false-positive rate. An increase in nonspecific proteins, as a result of the mixture of sera, may give rise to an increase in background color. With the pool size of 5 chosen for our study, and the change of the cutoff value from 2 to 1 , no losses in sensitivity (false negatives) or specificity (false positives) were observed.

The results of the present study show that the technique of pooling sera for the detection of HBsAg is highly sensitive and specific, and also permits considerable economic savings. These findings are similar to those obtained by other investigators who applied the method of pooling to the study of HCV and HIV infection (5-19). Up to the present, only two studies $(20,21)$ have been reported concerning the application of the pooling method to the study of HBV infection. In one of these (20), performed when carrying out routine antenatal screening for hepatitis $\mathrm{B}$ by testing 10 sample pools, the authors found a low prevalence of chronic carriers $(0.43 \%)$, and conclude that this is a cost-effective method and a valid strategy in areas of low seroprevalence, with a reduction in sensitivity estimated at $4.2 \%$. The application in our study of the pooling method to pregnant women, amongst whom the prevalence of chronic carriers of HBsAg is $0.93 \%$, demonstrated a sensitivity and specificity of $100 \%$.

The distribution of the two major subtypes of HBsAg (ad and ay) in our environment is approximately $50 \%$ for each one, ay being more frequent in drug addicts who use the parenteral route (22). We have demonstrated that the pooling method improves sensitivity, that is, decreases the detection limit of an immunoassay used for the determination of the two major HBsAg subtypes. Our pooling technique allows detecting quantities as small as 0.20 $\mathrm{ng} / \mathrm{mL}$ of $\mathrm{HBs} \mathrm{Ag} / \mathrm{ad}$, and $0.12 \mathrm{ng} / \mathrm{mL}$ of $\mathrm{HBsAg} / \mathrm{ay}$, even lower than those obtained with the standard method. The finding of increased sensitivity with pool testing is not surprising as this has been reported by other authors (16). It is important to assess the sensitivity of the EIA kit used for the pool test, because not all kits may be suitable for screening pools, as has been demonstrated in the case of antibodies against the hepatitis $\mathrm{C}$ virus $(23,24)$.

The presence of anti-HBs in the pool sera could modify the sensitivity of the technique, but only in a significant way in titers higher than $10,000 \mathrm{IU} / \mathrm{mL}$, seen only in samples from post-vaccination control studies; in this situation, the determination of HBsAg is not indicated. In fact, Cunninghan et al. (20) found that only $4.5 \%$ of pools made up with sera of pregnant women had an anti-HBs titer greater than 7,500 IU/L. Bearing in mind this limitation to the sensitivity of the pooling method, they found that this was also around $100 \%$ in sensitivity and specificity. Our results could be reproducible in other areas of low prevalence, but they should be demonstrated previously in areas with a high endemicity for HBV. In these areas, the majority of the population is already immunized against this virus, and it is possible that anti-HBs titers found in sera are slightly elevated.

Rabenau et al. (21) studied the safety of serologic tests in plasma pools for HBsAg using an EIA system similar to ours. In their study, the detection of HBsAg was influenced by the presence of low anti-HBs titers after 5 hours of incubation. However, following immune complex dissociation, HBsAg was still detectable in the pool even in the presence of high anti-HBs content. In our study we demonstrate that only a significant decrease in sensitivity results for anti-HBs titers higher than 10,000 IU/L. These differences can be due to the fact that in our case samples were tested without previous incubation. This could prevent antigen neutralization by immunocomplex formation.

We therefore believe that, both the titer of anti-HBs in serum and the pre-test processing of samples with EIA may influence pooling method sensitivity. Every laboratory desiring to use this technique should bear in mind these two factors before general use is implemented.

WHO recommends the use of the serum pooling method in case of HIV infection, when the prevalence of disease is less than $2 \%$, and with a maximum pooling of 5 sera (25). Following these indications, most studies apply and recommend the use of pooling techniques in areas of low seroprevalence. In our study, we demonstrate that the pooling of sera may also be cost-effective in populations with a high prevalence of HBsAg carriers. This could permit its use in countries belonging to areas of medium and high endemicity for HBV infection, which in general coincides with underdeveloped or developing countries, that is, those which have a greater need for reducing the economic costs involved in laboratory testing. Nevertheless, it will be necessary to carry out similar studies in these areas in order to confirm our results. However, it has already been demonstrated that in countries such as Kenya, which has a high frequency of HIV infection $(7.3 \%)$, the application of pooling for its detection would permit $62 \%$ economic savings with no significant loss in safety (14). In Spain, a country belonging to an area of low endemicity for HBV infection, and with a frequency of HBsAg carriers in the general population of $1.2 \%$ (4), it may be used in all those groups in which screening for HBsAg is currently mandatory (such as blood donors, subjects undergoing autotransfusion programs, screening of pregnant women).

The cost-benefit study of applying techniques for detecting chronic carriers of $\mathrm{HBV}$ allows to demonstrate 
that economic savings are greater when made in a large number of determinations in groups of low seroprevalence, and its use could also be cost-effective in areas with a high prevalence of infection, and even in laboratories carrying out a small number of determinations. We have shown economic cost savings according to both different HBsAg prevalence and number of tests to be performed annually. In our area, the application of the pooling method could save around $74 \%$ of total economic costs when compared to the single method.

Some investigators have recently begun to practice strategies for the detection of viral nucleic acids in blood donors using polymerase chain reaction (PCR) in order to increase the safety involved in the transfusion of blood derivatives (26-29). Due to the fact that it is not possible to carry out individual screenings because of economic problems and the amount of work involved, the method of pooling samples of serologically negative blood is now in use. This procedure might increase blood safety through a systematic screening of blood donations at a relatively low cost. Since one of the main limitations in practicing these methods is economical, we believe that, with our study, there could be a theoretical basis for the use of screening for $\mathrm{HBV}, \mathrm{HCV}$ and HIV infections in two stages at a relatively low economic cost. In the first phase a commercial EIA could be applied to a pool of donor sera; in the second phase, the application of PCR techniques to a pool of seronegative samples could increase the safety of the analysis. Until future studies can prove the value of this technique with blood donors, we believe that this could be applied only to diagnostic and epidemiologic testing.

We conclude that the application of EIA to pooled sera is a sensitive and specific method in the detection of the two major HBsAg subtypes in an area of low seroprevalence. Sensitivity only decreases when very high titers of anti-HBs exist in the pooled sera. The pooling technique is a method that may also permit financial savings if employed in the study of populations with a high prevalence of HBsAg carriers. We believe that further studies are necessary to confirm these findings.

\section{ACKNOWLEDGEMENTS}

We wish to thank David H. Wallace (a member of the European Association of Science Editors and the Council of Biological Editors) for the English language translation of the manuscript.

\section{REFERENCES}

1. Maynard JE. Hepatitis B: global importance and need for control. Vaccine 1990; 8 (Supl.): 18s-20s.

2. Margolis HS, Alter MJ, Hadler SC. Hepatitis B: evolving epidemiology and implications for control. Sem Liver Dis 1991; 11: 84-92.

3. Alter MJ, Mast EE. The epidemiology of viral hepatitis in the United States. Gastroenterol Clin North Am 1994; 23: 437-55.
4. Suárez A, Riestra S, Navascués CA, et al. Positive HBsAg blood donors in Asturias (Spain): current prevalence and its significance. (Engl abstract). Med Clin (Barcelona) 1994; 102: 329-32.

5. Emmanuel JC, Basset MT, Smith HJ, Jacobs JA. Pooling of sera for human immunodeficiency virus (HIV) testing: an economical method for use in developing countries. J Clin Pathol 1988; 41: 582-5.

6. Kline RL, Brothers TA, Brookmeyer R, et al. Evaluation of human immunodeficiency virus seroprevalence in population surveys using pooled sera. J Clin Microbiol 1989; 27: 1449-52.

7. Cahoon-Young B, Chandler A, Livermore T, et al. Sensitivity and specificity of pooled versus individual sera in a human immunodeficiency virus antibody prevalence study. J Clin Microbiol 1989; 27: 1893-5.

8. Frosner GG, Dobler G, von Sonnenburg FJ. Cost reduction of unlinked testing for anti-HIV by investigation of pooled sera. AIDS 1990; 4: 73-5.

9. Behets F, Bertozzi S, Kasali M, et al. Sucessful use of pooled sera to determine HIV-1 seroprevalence in Zaire with development of costefficiency models. AIDS 1990; 4: 737-41.

10. Monzon OT, Paladin FJ, Dimaandal E, et al. Relevance of antibody content and test format in HIV testing of pooled sera. AIDS 1992; 6: 43-8

11. Tamashiro H, Maskill W, Emmanuel J, et al. Reducing the cost of HIV antibody testing. Lancet 1993; 342: 87-90.

12. Perriens JH, Magazani K, Kapila N, et al. Use of a rapid test and an ELISA for HIV antibody screening of pooled serum samples in Lubumbashi, Zaire. J Virol Methods 1993; 41: 213-21.

13. McMahon EJ, Fang C, Layug L, Sandler SG. Pooling blood donor samples to reduce the cost of HIV-1 antibody testing. Vox Sang 1995; 68: 215-9.

14. Verstraeten T, Farah B, Duchateau L, Matu R. Pooling sera to reduce the cost of HIV surveillance: a feasibility study in a rural Kenyan district. Trop Med Int Health 1998; 3: 747-50.

15. Kamel MA, Ghaffar YA, Wasef MA, et al. High HCV prevalence in Egyptian blood donors. Lancet 1992; 340: 427.

16. Neil AGS, Conradie JD. Low cost anti-HCV screening of blood donors. Lancet 1992; 340: 1096.

17. Fernández E, Riestra S, García S, Rodríguez S. Pool tests for detection of hepatitis C virus infection. J Hepatol 1995; 23: 236.

18. García Z, Taylor L, Ruano A, et al. Evaluation of a pooling method for routine anti-HCV screening of blood donors to lower the cost burden on blood banks in countries under development. J Med Virol 1996; 49: 218-22

19. Liu P, Shi ZX, Zhang YC, et al. A prospective study of a serum-pooling strategy in screening blood donors for antibody to hepatitis $\mathrm{C}$ virus. Transfusion 1997; 37: 732-6.

20. Cunningham R, Northwood JL, Kelly CD, et al. Routine antenatal screening for hepatitis B using pooled sera: validation and review of 10 years experience. J Clin Pathol 1998; 51: 392-5.

21. Rabenau H, Schutz R, Berger A, et al. How accurate is serologic testing of plasma pools for hepatitis B virus surface antigen, anti-human immunodeficiency virus 1 and 2, and anti-hepatitis $\mathrm{C}$ virus? (Engl abstract). Infus Transfus 1996; 23: 124-30.

22. Echevarría JE, León P, López JA, et al. HBsAg subtype distribution among different populations of HBsAg carriers in Spain. Eur J Epidemiol 1995; 11: 39-45.

23. Neill AGS, Conradie JD. Pool tests for hepatitis C virus. Lancet 1994; 343: 738.

24. Liu P, Shi ZX, Zhang YC, Zhang XY. Comparative study on 4 EIA kits for screening antibody to hepatitis $\mathrm{C}$ virus in pooled sera. Biomed Environ Sci 1998; 11: 75-80.

25. Recommendations for testing for HIV antibody on serum pool. WHO Weekly Epidemiol Rec 1991; 44: 316-27.

26. Lefrere JJ, Coste J, Defer C, et al. Screening blood donations for viral genomes: multicenter study of real-time simulation using pooled samples on the model of hepatitis C virus RNA detection. Transfusion 1998; 38: 915-23.

27. Yerly S, Pedrocchi M, Perrin L. The use of polymerase chain reaction in plasma pools for the concomitant detection of hepatitis $\mathrm{C}$ virus and HIV type 1 RNA. Transfusion 1998; 38: 908-14.

28. Schottstedt V, Tuma W, Bunger G, Lefevre H. PCR for HBV, HCV and HIV-1 experiences and first results from a routine screening programme in a large blood transfusion service. Biologicals 1998; 26: 101-4.

29. Morandi PA, Schockmel GA, Yerly S, et al. Detection of human immunodeficiency virus type 1 (HIV-1) RNA in pools of sera negative for antibodies to HIV-1 and HIV-2. J Clin Microbiol 1998; 36: 1534-8. 